Article

\title{
Study of Arc Parameters of AC Relays Operating under Distorted Supply Voltage Conditions
}

\author{
Dariusz Smugala ${ }^{1, *(1)}$ and Michal Bonk ${ }^{2}$ \\ 1 Institute of Electromechanical Energy Conversion, Cracow University of Technology, Warszawska 24 Str., \\ 31-155 Cracow, Poland \\ 2 Department of Electrical and Power Engineering, AGH University of Science and Technology, \\ Mickiewicza 30 Str., 31-126 Cracow, Poland; bonkm@agh.edu.pl \\ * Correspondence: dariusz.smugala@pk.edu.pl; Tel.: +48-628-26-23
}

Received: 31 July 2020; Accepted: 11 September 2020; Published: 14 September 2020

\begin{abstract}
The paper presents a procedure for measuring and analyzing the switching arc parameters occurring in air-insulated low voltage (LV) relays operating in distorted supply voltage conditions. The main purpose of the research was the analysis of the switching arc duration and its energy affecting the current breaking capacity of the selected LV current interrupters (CI). The performed study and simple statistical analysis enabled the determination of the main factors and their impact level on parameters of the switching arc that comes about during switching-off operation. Experimental tests executed for various shapes of the supply voltage but similar RMS (Root Mean Square) and THD (Total Harmonic Distortion) values and for various breaking moments of the load current allowed recognition of the decisive factors for estimating the tested relay's switching-off capacity. Tests stand combined with dedicated software developed in the frame of the research, permiting fast calculation of the arc parameters based on a large number of recorded diagrams.
\end{abstract}

Keywords: arc energy; arcing time; current interrupters; energy quality; harmonics

\section{Problem Statement}

The problem of current harmonics developing within power networks has arisen since power electronic devices and non-linear load applications have become more common [1]. Replacing the electromechanical devices by electronic components, in general, positively affects reliability and functionality of the installed devices, but at the same time, can cause voltage and current distortion, and generation of current harmonics that can affect electric energy quality [2].

The presence of current harmonics in power networks negatively affects installed devices. Its destructive influence is observed on passive elements like cables or capacitors, i.e., decreasing their durability [3-6], and on active devices as well, e.g., switching apparatus or protective relays $[7,8]$. The presence of harmonics may result in power network components behaving unpredictably [9] or may cause deterioration of operating conditions.

The problem of the influence of the interrupted current and voltage shape on the levels of various kinds of generated surges during switching operations is known from literature [10]. Accordingly, power energy distorted sources threaten installed components and induce more severe power-down condition occurrences. Based on assumptions given in literature, an increased level of generated losses resulting from the presence of harmonics may be a source of premature aging of relay elements, e.g., contacts, or decreased effectiveness of the current interruption [11].

It is expected that supply source harmonics affect switching apparatus breaking efficiency, e.g., arcing time [12], the estimation of which, in the case of low voltage (LV) current interrupter (CI) usage, is the idea of the research presented here. 
In contrast to high energy switching processes, the problem does not seem to be clearly identified in the case of LV CIs and low energy switching operations. Taking into account the number of various kinds of widely used LV switching apparatuses, the problem of influence of the distorted supply source on the LV switching apparatus breaking capacity remains unsolved.

The authors are presenting a laboratory test method and the corresponding analysis procedure of the switching process realized by LV electromechanical CIs operating in the distorted currents that result from a supply voltage waveform shape.

The procedure of estimating the current breaking capacity is mainly based on measurements of the arcing time $\left(T_{a}\right)$ and switching arc energy $\left(E_{a}\right)[13-15]$.

There are several known ways of measuring the above mentioned quantities. An exemplary method grounded in direct measurement of the arc energy is that based on measuring the heat transfer rate using a copper slug calorimeter sensor [16]. Similar approaches are based on measuring arc radiation [17] or using a Rogowski coil [18]. Barring direct measurements of the arc energy, a combination of various methods is frequently applied.

By registering indirect quantities, $T_{a}$ and $E_{a}$ can be calculated using various optical diagnostics e.g., pyrometer and spectrograph [19], or utilizing a fast camera [20] and voltage-current diagrams for simultaneous registration of arc energy determination [21,22].

However, in order to acquire the desired quantities or values, a specialized and complex measuring system is necessary, and the measurement procedure is complicated.

For this reason, the most popular and widely used approach is that one based on simultaneous registering of voltage and current diagrams of the switching arc. Based on the obtained time-related voltage and current diagrams, the resultant $T_{a}$ and $E_{a}$ values are calculated. The obtained results of arcing time and arc energy indicate the ability of each apparatus to extinguish the switching arc. The main difference between the methods described in literature is the diverse hardware used for registration and the software applied for calculating the final quantities.

The method described in this paper may be used in the case of tests comprising large quantities of measurements. The Matlab application permits the automatic processing of unlimited amounts of data, in practice. The scope of the analysis can be easily extended through implementing additional modules.

The objects under research were CIs equipped with DC electromagnetic driving mechanisms, but the presented test and analysis method may be utilized for verifying potential variation in switching capacity parameters for different applied drives.

The research was focused on detailed analysis of the influence of the supply voltage harmonics content and shape of the interrupted current on the switching arc parameters of the selected LV CIs. The character of the specific research was mainly focused on analysis of the huge amount of collected data, and required application of a developed, dedicated software tool allowing for automation of the analysis process. The obtained results have been subjected to statistical analysis.

\section{The Measurement Procedure Specification}

The objects of the research are air-insulated LV CIs equipped with DC electromagnetic driving mechanisms. The main scope of the research was the registration and analysis of the switching arc occurring between the main contacts. Based on obtained results, the arc-quenching ability of tested interrupters was estimated. Thus, the breaking operation of the current flowing through the inductively loaded circuit was realized at the various current waveform breaking moments. For selection of the CI desired breaking moments, an additional driver had to be developed.

The tested object selection was dictated by the relatively simple approach of the selection of the desired breaking moments. We also recognized that LV current interrupters in the form of relays, contactors, circuit breakers etc., are the most popular switching apparatuses available in the market. Tests were executed on both single phase and three phase LV circuit breakers. In case of three-phase circuit breakers, only those following a single current path were used. 
For comparison purposes, interrupters characterized by varying current breaking efficiency were selected for testing, thus four types and three pieces of each type of interrupter were tested.

In view of the specific parameters of each electro-mechanic switching apparatus, the internal switching-off time interval, $\mathrm{T}_{\text {soff, }}$ had to be established (Table 1). Switching-off time is an effect of movable armature inertia, coil de-energization, and armature movement duration.

Table 1. Tested objects selected parameters.

\begin{tabular}{cccc}
\hline CI & Class & $\mathbf{I}_{\mathbf{n}}[\mathbf{A}]$ & $\mathbf{T}_{\text {soff }}[\mathbf{m s}]$ \\
\hline CI-1 & AC1 & 15 & 17 \\
CI-2 & AC3 & 15 & 20 \\
CI-3 & AC1 & 15 & 60 \\
CI-4 & AC3 & 15 & 22 \\
\hline \multicolumn{5}{c}{}
\end{tabular}

Compensation of the movable armature inertia was realized using predictive control of the driving coil supply voltage.

Taking into account the form of the driving mechanism, an additional recognition of the operation parameters of the tested devices was needed. The diverse parameters include tripping time $\left(T_{0}\right)$, this being the time between the moment of supply voltage $U_{s}$ disconnection at the driving coil terminals and the moment of armature movement start-up. These conditions in turn affect the switching-off time interval $\left(T_{\text {soff }}\right)$, this being the sum of $T_{0}$ time interval and armature movement duration $T_{m}(1)$.

$$
\mathrm{T}_{\mathrm{soff}}=\mathrm{T}_{0}+\mathrm{T}_{\mathrm{m}}
$$

During the experiment, the contact-breaking moment was recognized by means of establishing the voltage drop at the main contact $\mathrm{U}_{\mathrm{c}}(\mathrm{t})(2)$. By registering the supply voltage disconnection moment and the contact-breaking moment as recognized by the appearance of the $U_{c}(t)$ voltage, the switching-off time could be determined (2).

$$
T_{\text {soff }}=t_{c}\left(U_{c}=U_{G}\right)-t\left(U_{s}=0\right)
$$

where:

$\mathrm{U}_{\mathrm{G}}$-generator output voltage signal, $\mathrm{t}_{\mathrm{c}}\left(\mathrm{U}_{\mathrm{c}}=\mathrm{U}_{\mathrm{G}}\right)$-the main contacts breaking moment, $t\left(U_{s}=0\right)$-moment of the coil's supply disconnection.

To ensure that the contacts broke at the specified moment, an interrupter drive control circuit (based on an Atmega 8535 chip) was elaborated. Measuring the switching-off time of each tested interrupter was realized for the rated voltage. Thirty switching-off operations for each object were

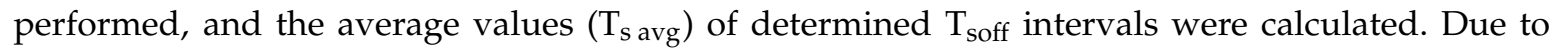
statistical reasons and in order to limit the impact of manufacturing inaccuracies of each tested piece, 3 pieces of each CI type were tested.

Taking into account the additional time required for contact breaking (resulting from $T_{o}$ and $T_{m}$ presence), the driver disconnected the supplying voltage in advance. The controller circuit allowed for selecting the moment of de-energization of the driving coil with respect to the expected contact-breaking moment. The achieved accuracy of contacts breaking selection was around $0.2 \mathrm{~ms}$.

The general idea of the controller operation is presented in Figure 1. Herein, synchronization signals $\mathrm{V}_{\mathrm{o}}$ (Figure 1a) were obtained using a "zero" detector, the construction of which is based on a LM111 voltage comparator. 


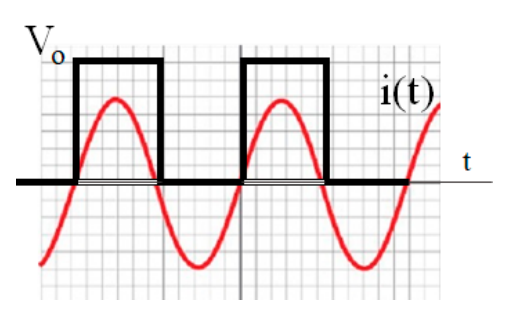

(a)

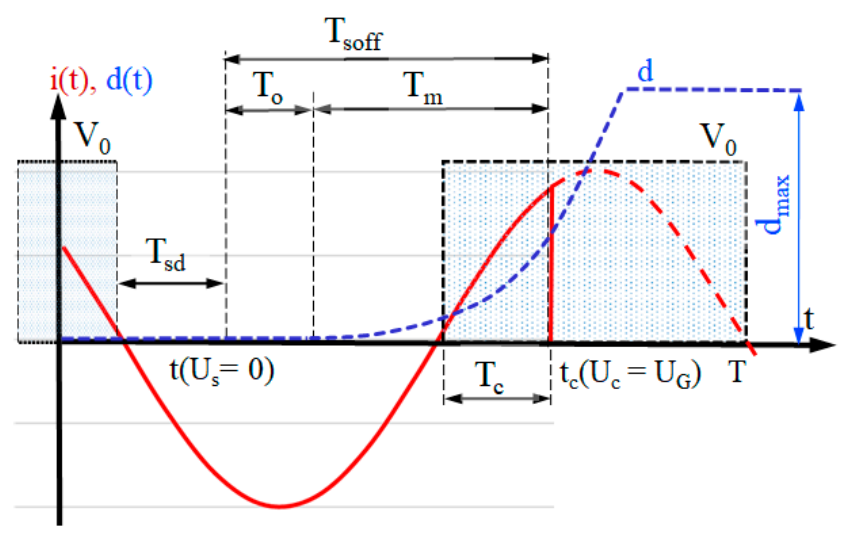

(b)

Figure 1. The procedure of realizing contact breaking at the specified moment of the signal waveform: (a) synchronization signals (b) contacts breaking moment selection; $\mathrm{V}_{0}$ - "zero" synchronization pulses, $\mathrm{t}\left(\mathrm{U}_{\mathrm{s}}=0\right)$-supply voltage disconnection moment, $\mathrm{T}_{\mathrm{sd}}$-delay of coil supply disconnection, $\mathrm{t}_{\mathrm{c}}\left(\mathrm{U}_{\mathrm{c}}=\mathrm{U}_{\mathrm{G}}\right)$-contacts breaking moment, $\mathrm{T}_{\mathrm{c}}$-contacts breaking delay (in relation to waveform "zero"), $\mathrm{d}$-armature movement path, $\mathrm{d}_{\max }$-maximum air gap.

The square wave generated by the detector was utilized to set a delay time $\mathrm{T}_{\mathrm{sd}}$ for obtaining the voltage disconnection moment. In cases when $T_{\text {soff }}$ was shorter than the half-wave of the current period, $\mathrm{T}_{\mathrm{sd}}$ time provided the required delay for switching realization to the selected phase. In cases where $T_{\text {soff }}$ was longer than the half-wave of the current, the $T_{\text {sd }}$ time was increased by $10 \mathrm{~ms}$.

Having already determined switching-off time $\mathrm{T}_{\text {soff }}$ and $\mathrm{T}_{\mathrm{sd}}$ time, the supply voltage disconnection moment $t\left(U_{s}=0\right)$ (realized at a specified advance of $T_{\text {soff }}$ time) was calculated as a sum of both times (Figure 1b). This feature was utilized for analyzing the distorted load current breaking phase impact on the switching arc parameters.

The measuring stand (Figure 2) permitted registering the voltage/current signals combinations under specific supply voltage conditions. The inductive character load, being the most frequently found load type, was used.

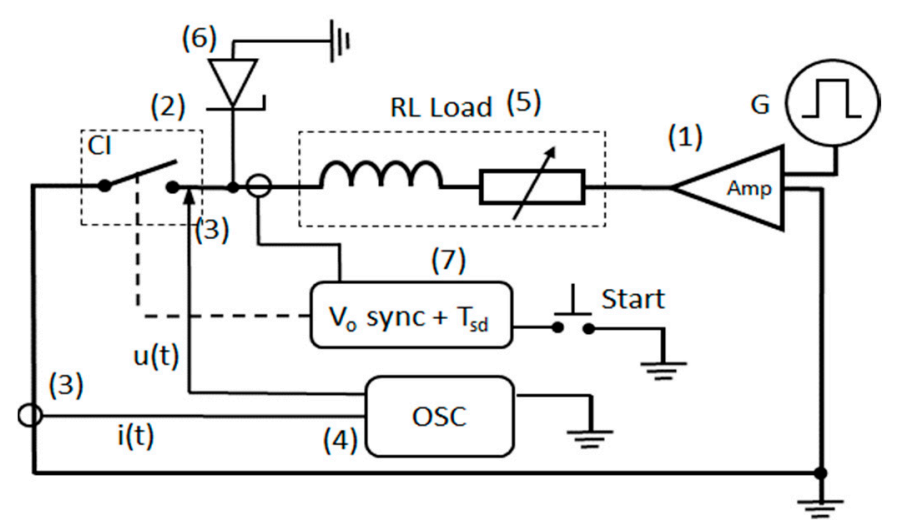

Figure 2. Testing stand diagram.

The testing stand comprised the following elements:

- $\quad$ arbitrary generator $(\mathrm{G})$ coupled with a high efficiency, low noise amplifier (Amp); this represents the power supply source (1) and is able to generate the desired output signal,

- tested LV current interrupter-CI (2),

- voltage and current probes (3),

- digital oscilloscope (4), 
- load (5) comprising resistive $\mathrm{R}=14 \Omega$, and inductive elements $\mathrm{L}=19 \mathrm{mH}, \mathrm{XL}=6,3 \Omega, \cos \varphi=0.92$,

- optional voltage surge limiting element (6),

- $\quad$ switching-off phase controller (7).

The value of the parameters of inductive load was necessitated by the need to meet international standards that establish the maximum value of a reactive power allowed for municipal and industrial customers. The load utilized for tests contained air coils and connected the resistors in series.

An arbitrary generator was used as source of distorted waveforms. Based on assumed harmonic content (number, amplitude), the desired signal shape was created using dedicated software and then transferred into the generator. Because of the minimal energy of the generated waveforms, typically not exceeding $10 \mathrm{~V}$ and $100 \mathrm{~mA}$ of output current, an additional amplifier had to be used.

For this purpose, an amplifier of our own design was applied. This was based on the author's own design, an Australian project study of Eliott Sound Product called Project 117 [23]. Basic rated parameters of the designed construction have been collected in Table 2.

Table 2. Amplifier basic parameters.

\begin{tabular}{ll}
\hline \multicolumn{1}{c}{ Parameter } & \multicolumn{1}{c}{ Value } \\
\hline Max. output voltage [V] & $100 \mathrm{AC}$ at $50 \mathrm{~Hz}$ \\
Input current signal level [mA/V] & $100 \mathrm{~mA} / 1.7 \mathrm{AC}$ \\
Max output current [A] & 15 at $50 \mathrm{~Hz}$ at $100 \mathrm{~V}$ \\
Bandwidth [Hz] & $20-20,000$ \\
Nonlinear distortions [\%] & $\leq 1$ \\
\hline
\end{tabular}

Considering the goal of the experiment, the key task during the developing process of the amplifier was to avoid any distortion of the output signal. Realization of this was feasible by means of building a power supply with low internal impedance and without any electronic power components. With this design, output voltage ripples could be minimized.

In the first step of the research, selected voltage signal waveforms were generated. In the tests, the group of voltage waveforms were selected according to current harmonic values typically encountered in common power networks [24]. For each of the voltage waveforms applied during experiment, the THD factor was determined.

Generally, electricity quality is described by two factors: voltage stability and THD factor. For this reason two groups of examined voltage waveforms were described by identical RMS and THD factors, but different shapes and amplitudes. In total, 12 signal waveforms, including sine and triangle, were tested (Figure 3, Table 3). The signal criteria selection was the assumed incidence rate in the power network in case of presence of non-linear devices. THD and RMS values of the sinusoidal signal were used as reference.

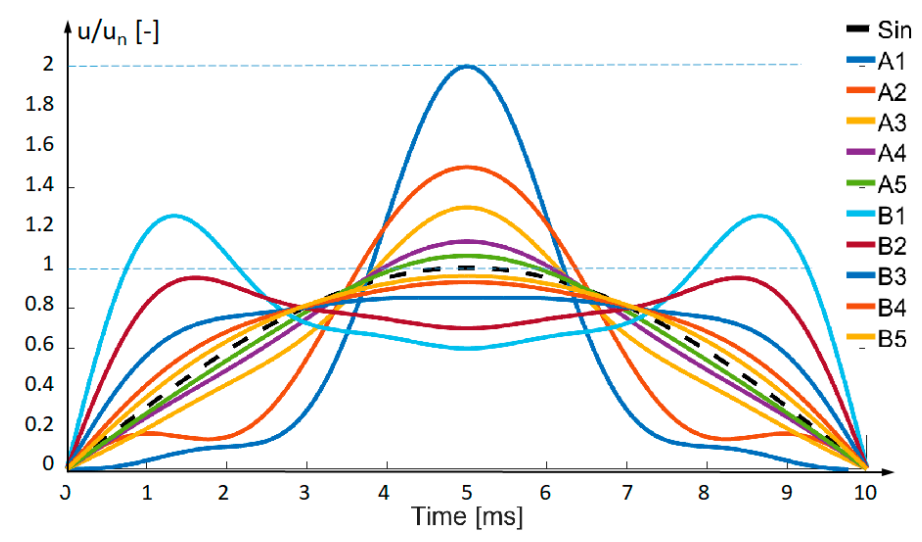

Figure 3. Supply voltage signal power amplifier. 
Table 3. Input signals parameters (harmonic's amplitudes and phases).

\begin{tabular}{ccccccccccccccccc}
\hline Harm No. & {$[\%]$} & {$[\mathrm{rad}]$} & {$[\mathrm{rad}]$} & {$[\%]$} & {$[\mathrm{rad}]$} & {$[\mathrm{rad}]$} & {$[\%]$} & [rad] & [rad] & {$[\%]$} & {$[\mathrm{rad}]$} & {$[\mathrm{rad}]$} & {$[\%]$} & {$[\mathrm{rad}]$} & [rad] \\
\hline \multirow{2}{*}{ Signal } & A1 & \multirow{2}{*}{ A1 } & B1 & A2 & A2 & B2 & A3 & A3 & B3 & A4 & A4 & B4 & A5 & A5 & B5 \\
& B1 & & & B2 & & & B3 & & & B4 & & & B5 & & \\
\hline 1 & 100 & 0 & 0 & 100 & 0 & 0 & 100 & 0 & 0 & 1 & 100 & 0 & 100 & 0 & 0 \\
3 & 60 & $\pi$ & 0 & 30 & $\pi$ & 0 & 20 & $\pi$ & 0 & 3 & 10 & 0 & 5 & $\pi$ & 0 \\
5 & 30 & 0 & 0 & 15 & 0 & 0 & 7.5 & 0 & 0 & 5 & 3 & 0 & 1 & 0 & 0 \\
7 & 10 & $\pi$ & 0 & 5 & $\pi$ & 0 & 2.5 & $\pi$ & 0 & - & - & - & - & - & - \\
\hline
\end{tabular}

During the main part of the experiment, the voltage signals obtained from the generator powered the testing circuit. The RMS values of the testing voltage waveforms were controlled through the amplifier. This approach allowed for the desired signal shape to have sufficient energy to initiate a switching arc between the interrupter contacts.

Distorted current flow caused by distorted voltage signals was subsequently interrupted at the specific phase $\varphi$ of each waveform.

For experimental purposes, the other signals were considered to hold amplitude values in reference to the sine wave. The adoption of such an assumption enabled the incorporation of the various amplitude values of the applied signals within the achieved data.

In view of the chosen driving method, the various switching-off times of the tested devices were realized using the developed driver circuit. Four contact-breaking moments $\varphi$ of the waveform were selected for tests: $0^{\circ}+, 45^{\circ}, 90^{\circ}, 135^{\circ}$. The " $0+^{\prime \prime}$ moment is the current breaking moment right after the "zero" value crossing point. In practice, the contact opening moment was realized within $1 \mathrm{~ms}$ after the zero-crossing point.

Initially, tests were executed for voltage/current ratios: $\mathrm{U}_{\mathrm{RMS}}=100 \mathrm{~V}, \mathrm{I}_{\mathrm{RMS}}=5.5 \mathrm{~A}$. , according to the circuit's maximum power capabilities. For each measurement case, 30 contact opening operations were executed and their voltages and currents waveforms recorded.

Finally, data obtained by means of oscilloscopic measurements was analyzed in view of the arc parameters generated during the switching-off process with respect to input voltage and the resultant current shape: arcing time and generated arc energy. Based on the recorded diagrams, which had the graphical form *.jpg for quick inspection, and the numerical form *.csv for mathematical post-processing, final desired quantities were calculated for each of the executed current interruption operations:

- $\quad$ arcing time- $-\mathrm{T}_{\mathrm{a}}$,

- number of arc re-ignitions $\left(\mathrm{n}_{\mathrm{a}}\right)$ - if these occurred,

- total arc energy- $\mathrm{E}_{\mathrm{a}}$,

The resulting data was stored in the form of an Excel *.xls output file, containing calculated data.

\section{Measurements Data Post-Processing}

So as to generate a comprehensive range of the performed analysis, the study required more than 17,000 diagrams for single supply voltage and current RMS conditions. For post-processing needs, each of the registered waveforms was divided into three time intervals (Figure 4): I-voltage drop at the closed contacts (voltage noise signal), II—arcing time $-\mathrm{T}_{\mathrm{a}} / \operatorname{arc}$ voltage $-\mathrm{u}_{\mathrm{a}}(\mathrm{t})$, III-voltage oscillations at of the inductively loaded circuit; while four moments were specified: $t_{1}$-registration starting point, $t_{0}$-current's zero-crossing, $t_{2}$-arc burning starting moment (contact-breaking moment $t_{c}$ in Figure 1 ), $t_{3}$-arc quenching moment, $t_{4}$-registration finishing point.

The contact breaking delay can be subsequently derived from (3):

$$
\mathrm{T}_{\mathrm{c}}=\mathrm{t}_{2}-\mathrm{t}_{0}
$$




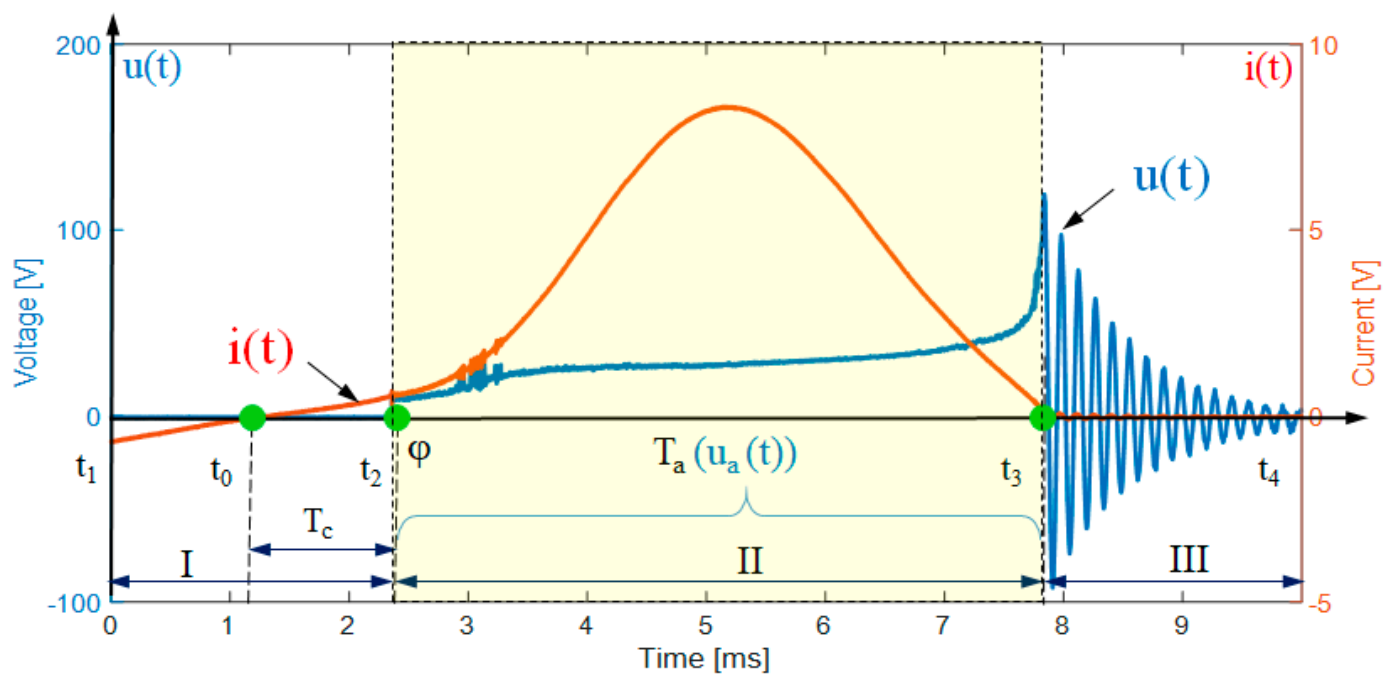

Figure 4. Exemplary recorded waveforms of load current and voltage across the contacts registered during CI-1 contact breaking for the A1 supply voltage signal.

Herein, $\mathrm{T}_{\mathrm{c} 0}$ is assumed to be the delay time set at the controller, at the initial data selection stage. Within the run of the experiment, 20 records containing data (from initial 30) of minimum value of $T_{C}$ and $\mathrm{T}_{\mathrm{c} 0}$ subtraction were achieved and selected for further post-processing, wherein (4):

$$
\min \left(\left|\mathrm{T}_{\mathrm{c}}-\mathrm{T}_{\mathrm{c} 0}\right|\right)
$$

For each combination of the recorded voltage-current signals, resultant arc energy $-\mathrm{E}_{\mathrm{a}}$ and arcing time $-\mathrm{T}_{\mathrm{a}}$ were calculated.

Because of the large number of waveforms recorded during the experiment, for analysis process automation, a dedicated software tool for analysis procedure improvement was developed through Matlab script. The elaborated software automatically performed resultant data download from the obtained measurements, calculated the required quantities and generated the output file.

The Matlab script used as input data *.csv text files obtained from oscilloscope readings that contained recorded voltage and current waveforms in numerical form. The output files had the form of *.xls files and held arc energy $-\mathrm{E}_{\mathrm{a}}$, arcing time $-\mathrm{T}_{\mathrm{a}}$, standard deviation (SD) values and the coefficient of variation $(\mathrm{CV})$ values as calculated for each of the calculated quantities of the recorded measurement for each case. Figure 5 presents a diagram of the developed Matlab script.

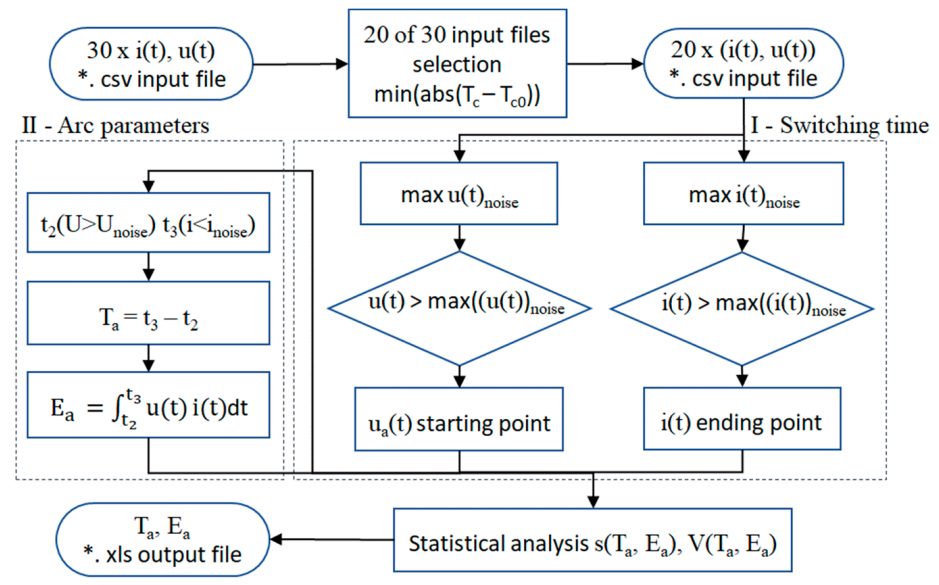

Figure 5. Matlab script operation diagram: $\max u(t)_{\text {noise, }}$ max $i(t)_{\text {noise }}$-maximum value of voltage and current noise signal, $\mathrm{u}_{\mathrm{a}}(\mathrm{t}), \mathrm{i}_{\mathrm{a}}(\mathrm{t})$ - voltage and current time related arc parameters. 
The main tasks for the developed software were:

- to collect all necessary data from the input *.csv files obtained from the oscilloscope

- to determine arc burning starting and ending moments (block I in Figure 5)

- to calculate arcing time and arc energy (block II in Figure 5)

- to perform statistical analysis of the obtained results

To determine the arc burning starting point, voltage across the contacts was monitored. Because of the imperfect contact between the interrupter's contacts, voltage drop at the input terminals was observed. This choice of action was particularly important for the relatively higher current values. Recorded voltage drop at the closed contacts was assumed to be noise signal $-\mathrm{u}(\mathrm{t})_{\text {noise }}$.

The first sample with recorded voltage level higher than assumed noise maximum signal$\mathrm{u}(\mathrm{t})_{\text {noise }}$-recorded between $\mathrm{t}_{1}$ and $\mathrm{t}_{2}$ points (I time interval in Figure 6 ), is considered as the arc burning starting point. Similarly, time of arc burning finish was determined as the point on the diagram of the current where the signal value $i_{\text {arc }}(t)$ equals the noise maximum value signal $i(t)_{\text {noise }}$ recorded between the $t_{3}$ and $t_{4}$ points (see Figure 4 ).

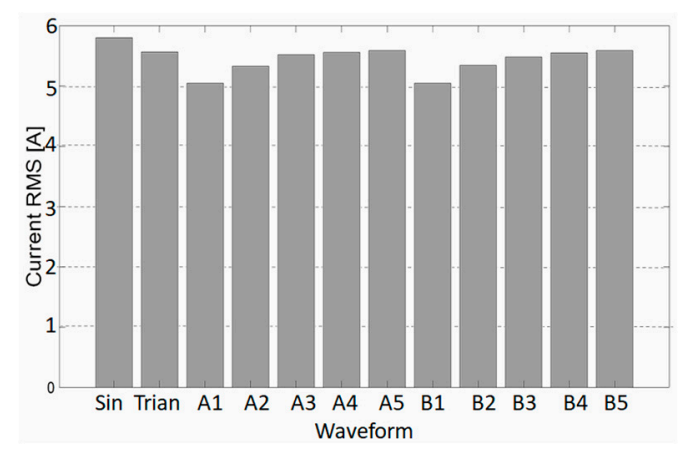

Figure 6. RMS values of load currents caused by the related voltage waveforms.

Arcing time $T_{a}$ was calculated as result of the subtraction between $t_{2}$ and $t_{3}$ moments (5).

$$
\mathrm{T}_{\mathrm{a}}=\mathrm{t}_{3}-\mathrm{t}_{2}
$$

Arc burning starting and ending points determined arc energy by employing (6).

$$
E_{a}=\int_{t_{2}}^{t_{3}} u_{a}(t) \cdot i_{a}(t) d t
$$

In view of the large number of performed measurements, the obtained results were analyzed statistically.

The full statistical procedure contained the following elements:

1. Initially, 20 measurement records were selected that were characterized by minimum contact breaking delay time $T_{\mathrm{C}}$ (see Figures 1 and 4 ) difference, in comparison to the value set at the driver breaking phase according to (3) and (4).

2. Arcing time and arc energy for each of the recorded cases were then calculated, and average values for each measurement series were obtained. All outliers were eliminated during preliminary analysis.

3. Standard deviation and similarity coefficient parameters for each of the results were calculated.

4. From the remaining results, maximum acceptable value of similarity coefficient for $T_{a}$ and $E_{a}$ were assumed at the $20 \%$ level.

5. At the final stage coefficients of variation for energy and arcing time were calculated. 
Thus, at the initial stage of the analysis, we selected only records with the minimum difference between the $T_{c 0}$ value set at the controller and the $T_{c}$ value achieved during the experiments. This was undertaken to minimize the influence of the $\mathrm{T}_{\mathrm{c}}$ parameter on measured $\mathrm{T}_{\mathrm{a}}, \mathrm{E}_{\mathrm{a}}$ quantities.

\section{Results Analysis}

The primary goal of the research was to identify the main factors related to the quality of the power source that affected the switching capacity of the tested relays. In the work, the independence of measurement resulting from the imprecision of switching phase $\mathrm{T}_{\mathrm{c}}$ selection allowed for recognition of the factors affecting arcing time and arc energy measured results.

A preliminary analysis of the obtained results generates the conjecture that the THD value of the supplied voltage and load current is not a decisive factor when drawing definitive conclusions about circuit breaker breaking efficiency estimation. This initial supposition was confirmed by the fact that, in accordance with Figure 3, several of the supplying voltage waveforms had similar THD values, but different shapes. In this connection, for estimating the interrupter breaking efficiency, additional factors were examined. According to (6), voltage, current shape (RMS values in Figure 6), and arcing time play key roles for establishing arc energy.

Moreover, supply voltage distortion levels and load current distortion, were analyzed simultaneously. In addition, distortion levels of the recorded voltage and current waveforms have effects on the calculated integral of voltage $u_{a}$ and current $i_{a}$.

For arcing time, beside the executed contact-breaking moment, voltage level and the rate of rise of the voltage waveform between the main contacts and current momentary value are important. High rate of rise of the voltage waveform between the breaker contacts may induce situations where electric field strengths greater than dielectric strength occur at the contact gap. In contrast, low current value may result in interruptions of the current when a chopping current value has been reached. This relationship was examined through the implementation of various breaking moments. As a result, arc burning duration and its energy depend on various parameters and mutual interactions.

Figure 7 presents calculated average arc energy values for the devices listed in Table 1 as CI- 1 and CI-2 with regard to various testing voltage signals and diverse current breaking moments $\varphi$.

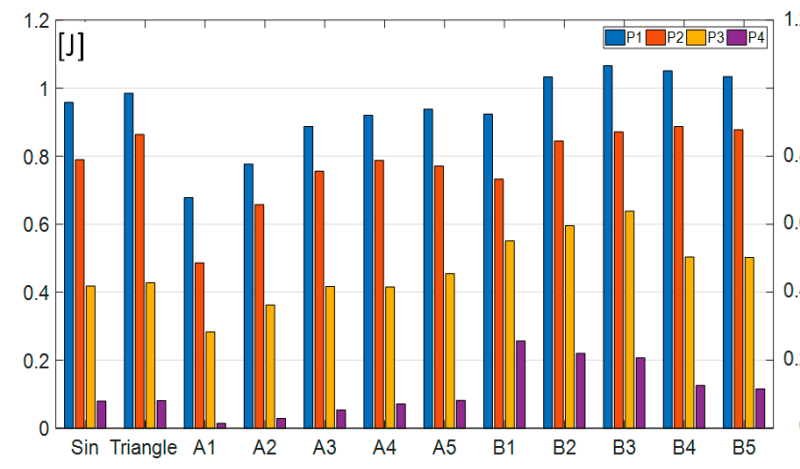

(a)

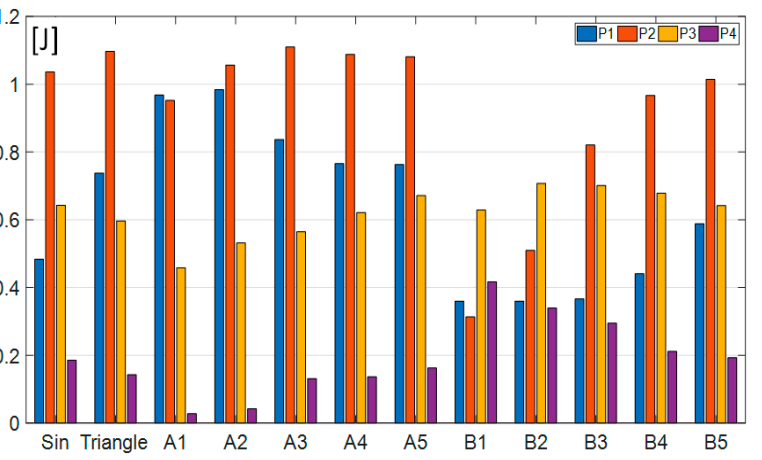

(b)

Figure 7. Average arc energy $E_{a}$ calculated for voltage waveforms for: (a) CI-1 (b) CI-2.

As expected, as indicated in (6), arc energy calculated for various breaking moments varies according to arcing time: a smaller phase of the contact-breaking moment results in a higher arc energy, assuming the same conditions. This trend is observed for all presented groups of results and for both relays. Similar dependency was observed for CIs marked as CI-3 and CI-4.

In the case of current waveforms induced by the A1-A5 voltage waveforms. The chopping current values were reached faster than for currents induced by the B1-B5 waveforms. Resulting arc energy for A-type waveforms reached lower values than did B-type waveforms. Because the rated currents of 
CI-1 (9 A) and CI-3 (6 A) are lower than the rated current of CI-2 and CI-4 (25 A), it is expected that CI- 1 and CI-3 relays have lower arc-quenching capacity to that of CI-2 and CI-4.

Figure 8 reveals the calculated arcing time $\mathrm{T}_{\mathrm{a}}$ for relays CI-1 and CI-2 for various voltage signals that have similar THD factor values, and for each of the current breaking moments. It is notable therein that the arc between the contacts of $\mathrm{CI}-1$ and $\mathrm{CI}-3$ has more favorable conditions for burning than that of CI-2 and CI-4, and the resulting arcing time for CI-1 (CI-3) is significantly longer than for CI-2 (CI-4).

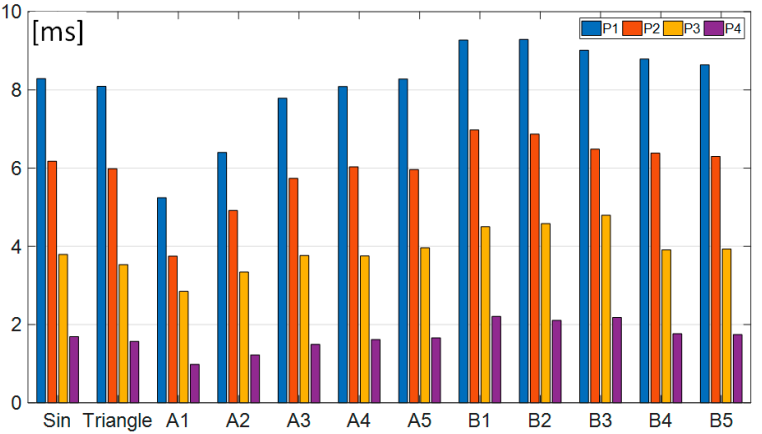

(a)

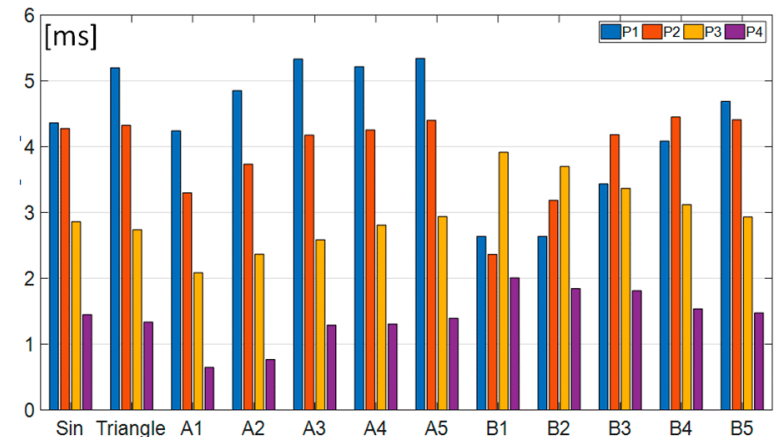

(b)

Figure 8. Average arcing times $\mathrm{T}_{\mathrm{a}}$ of: (a) CI-1 (b) CI-2 measured for voltage waveforms.

Circuit breakers characterized by higher current breaking efficiency are able to break the current faster than can devices intended for operation under lower current conditions. Our data indicates that the chopping currents of the CI-2 and CI-4 are higher than the chopping currents of the CI- 1 and CI-3. As a consequence longer arc burning is observed for CI-1 and CI-3 relays.

Considering the specific shape of the B-type waveforms, in that these have two extreme values (see Figure 4), the chopping current values suitable for arc quenching occurred twice in a wave half-period. Then, the arc was extinguished after the first maximum. At the next wave maximum, the distance between the relays' contacts was large enough and the dielectric strength of the contact's gap was high enough to prevent potential restrike.

For A-type waveforms, only a single maximum value occurred. Therefore, arc quenching was observed at the falling edge of the current waveform at the gradual deterioration of conditions for arc burning. In the course of the study, SD and CV parameters were calculated for all circuit breakers for arc energy and arcing time (Figures 9 and 10). This allowed estimating the variability of the measured parameters with respect to the accuracy of the applied measuring method.

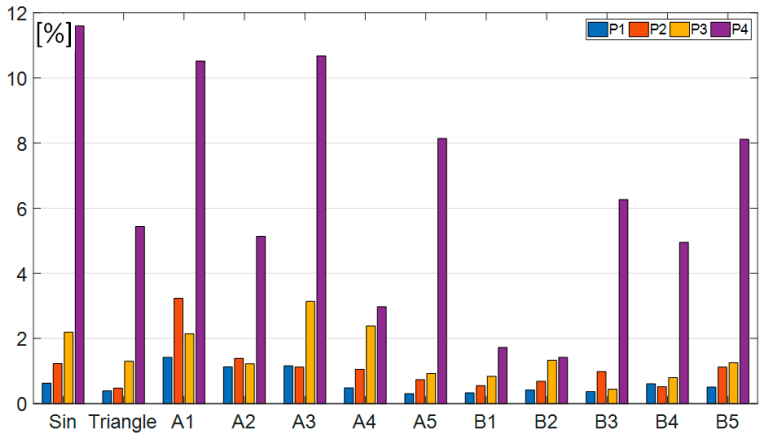

(a)

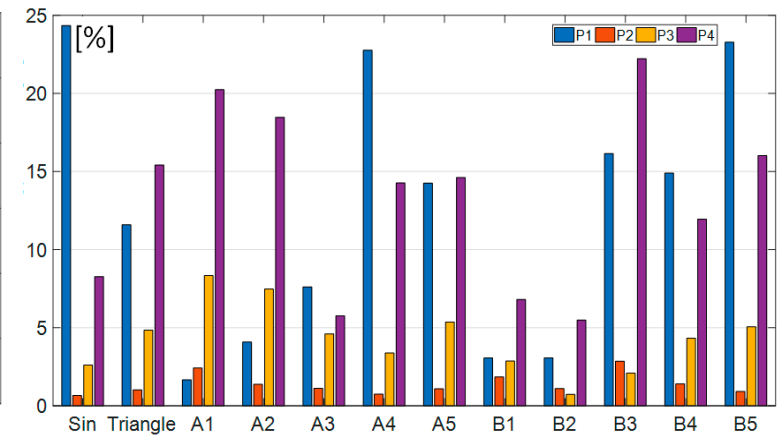

(b)

Figure 9. Coefficient of variation for energy (CVE) for: (a) CI-1 (b) CI-2. 


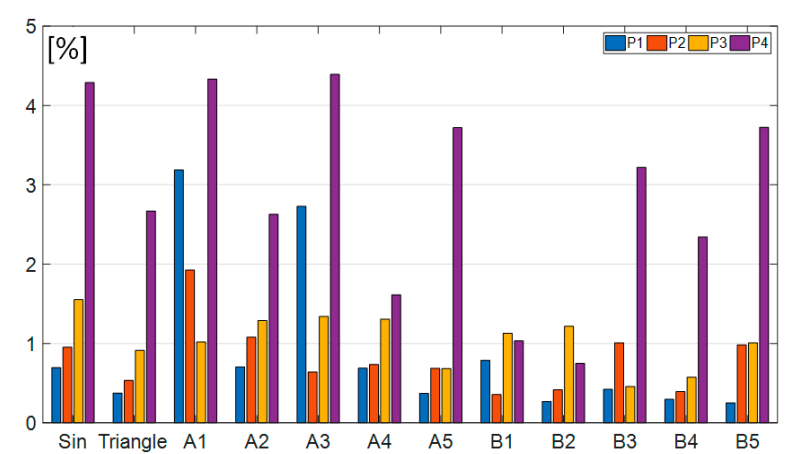

(a)

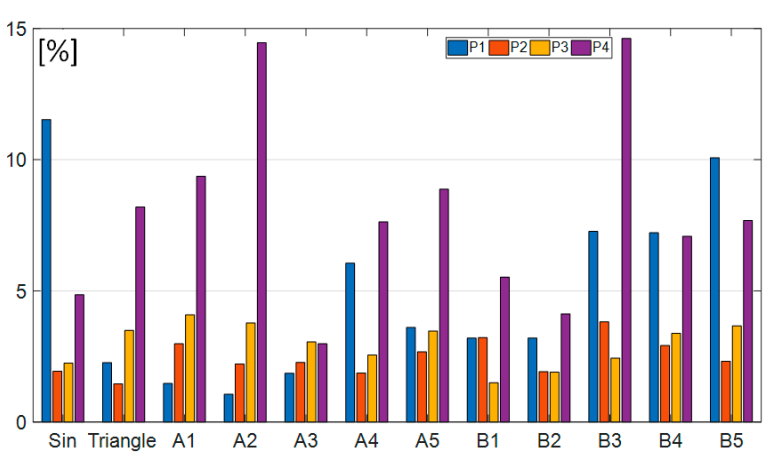

(b)

Figure 10. Coefficient of variation for arcing time (CVT) for: (a) CI-1 (b) CI-2.

The dispersion of results observed for CI-2 normally operating with higher rated currents were considered significant, especially for " $0+$ " current breaking moments. This effect may probably be explained by the CI-2 relay's higher arc-quenching efficiency.

Assuming that relays dedicated for interruption at lower current values (CI-1, CI-3) contain relatively less efficient arc-quenching systems, easier conditions for arc ignition are anticipated. As a consequence, more often, arc ignition can be observed and lower dispersion of results are notable.

In case of CIs equipped with high efficiency arc-quenching chambers (CI-2, CI-4), the arc ignition phenomenon may not occur because of insufficient conditions for arc ignition or because of faster arc-quenching realization. This effect can be observed especially for A-type waveforms with a slightly rising edge at the beginning and low power of arc at the initial stage.

Because of the same reasons, CI-2 and CI-4 devices intended to operate with higher currents may be able to break a current much earlier than other constructions. Arcing time thus may depend on external conditions, e.g., air gap and contact condition.

Waveforms characterized by higher energy at the beginning may negatively affect air gap condition at the initial arc burning stage, resulting in longer discharge time. At the same time, high efficiency of the quenching chamber may cause rapid arc quenching and prevent potential restrikes.

The achieved coefficient of variation for arcing time of CIs equipped with less efficient current breaking systems did not exceed $5 \%$. The coefficient of variation for energy was lower than $12 \%$. At the same time, achieved values of CVT and CVE for CIs equipped with more efficient current breaking systems did not exceed $15 \%$ for arcing time and $25 \%$ for arc energy.

\section{Summary and Discussion}

The test results presented in this paper were obtained as a result of experiments performed utilizing various types of current interrupters equipped with electromagnetically actuated driving mechanisms. The specific form of driving mechanism employed allowed for full control of the current breaking moment. Achieved accuracy of the contact-breaking moment selection was at a level lower than $0.2 \mathrm{~ms}$ and the applied analysis method excluded the impact of contact-breaking moment realization inaccuracy on the obtained results of the measured arc parameters.

Several input signal waveforms characterized by various shapes and THD factor values were utilized as the supply voltage of the testing circuit. The performed analysis indicates the higher impact of the voltage form prior to the harmonic component level indicated by the THD factor. This fact is confirmed by the utilization of supply waveforms characterized by the same (or similar) THD factor, but of different shape. Therefore, THD value-commonly used as an assessment of suppling source quality-is not a decisive factor when drawing definitive conclusions on circuit breaker breaking efficiency estimation. All measurement results performed in similar conditions confirm this trend. Hence, in actuality, RMS values of the voltage drop at the current interrupter contacts and RMS values of the current flowing through the contacts define the burning arc energy and resulting CI breaking efficiency. 
On interrupting the waveforms comprising more than single maximum values by interrupters dedicated for operation under the most popular AC-3 utilization categories, the chopping current value is reached faster than in the case of waveforms comprising single maximums. In consequence, the arc was extinguished after the first waveform maximum and arcing times for waveform comprising more than single maximums were shorter. Thus, arc-breaking capacity for these types of waveforms is higher.

Due to the huge amount of data that had to be analyzed, automation processing was applied for improvement of the experimental data post-processing. The developed software allowed for automatic generation of the resultant data based on results obtained in each frame of each measurement series.

The applied script can be utilized for various types of input numerical data. After minor modification, it can also be adapted for recognizing circuit breaker parameter variation during the entire life span.

By enabling the modification of the testing circuit (e.g., load type or supply parameters) and customizing the developed script, the presented measuring method can be used for determining the impact of various types of non-linear loads on disparate CIs characterized by diverse current breaking capacity.

Author Contributions: Conceptualization, D.S. and M.B.; methodology, D.S. and M.B.; software, M.B.; validation, M.B.; formal analysis, D.S. and M.B.; investigation, D.S. and M.B.; resources, D.S. and M.B.; data curation, M.B.; writing — original draft preparation, D.S.; writing — review and editing, D.S.; visualization, D.S. and M.B.; supervision, D.S.; project administration, D.S.; All authors have read and agreed to the published version of the manuscript.

Funding: This research received no external funding.

Conflicts of Interest: The authors declare no conflict of interest.

\section{References}

1. Neagu, C.; Scarlatache, G.; Gheorghe, F. The Influence of Harmonics on Power Losses in Urban Distribution Networks. In Proceedings of the International Symposium on Fundamentals of Electrical Engineering, Bucharest, Romania, 30 June-2 July 2016; pp. 1-4.

2. Khan, S.; Singh, B.; Makhija, P. A Review on Power Quality Problems and its Improvement Techniques. In Proceedings of the Innovations in Power and Advanced Computing Technologies, Vellore, India, 21-22 April 2017; pp. 1-7.

3. Noshahr, J.B.; Bagheri, M.; Kermani, M. The Estimation of the Influence of Each Harmonic Component in Load Unbalance of Distribution. In Proceedings of the IEEE International Conference on Environment and Electrical Engineering and 2019 IEEE Industrial and Commercial Power Systems Europe, Genova, Italy, 11-14 June 2019; pp. 1-6.

4. Chenying, L.; Jie, C.; Libin, H.; Jingying, C. Simulation and Analysis of Power Cable Harmonic Loss and Temperature Rise. In Proceedings of the International Conference on AC and DC Power Transmission, Beijing, China, 28-29 May 2016; pp. 1-6.

5. Wan, D.; You, K.; Zhou, H.; Qi, F.; Peng, S.; Peng, T. Study on Harmonic Load Loss Calculation Method of Oil-Paper Insulated Distribution Power. In Proceedings of the IEEE conference on Energy Internet and Energy System Integration, Changsha, China, 8-10 November 2019; pp. 2746-2749.

6. Ghosh, R.; Chatterjee, B.; Chakravorti, S. Investigations on the Effect of Voltage Harmonics on Leakage Current for Condition Monitoring in Insulators. In Proceedings of the IEEE International Conference on Power Systems, New Delhi, India, 4-6 March 2016; pp. 1-5.

7. Wannous, K.; Toman, P.; Pozzobon, P. Effect of Total Harmonics Distortion on Distance and Overcurrent Relays. In Proceedings of the International Scientific Symposium on Electrical Power Engineering, Stará Lesná, Slovakia, 16-18 September 2017; pp. 670-674.

8. Ankita, B.; Kumar, J.S. A review of Literature on Effects of Harmonics on Protective Relays. In Proceedings of the IEEE Innovative Smart Grid Technologies, Singapore, 22-23 May 2018; pp. 407-412. 
9. Yoshida, K.; Sawa, K.; Suzuki, K.; Watanabe, M.; Daijima, H. Analysis of Asymmetrical Component Influence on Arc Current in the Determination of Arc Thermal Performance Value of Protective Personal Equipment. IEEE Trans. Ind. Appl. 2019, 55, 2130-2137.

10. Wannous, K.; Toman, P. Evaluation of Harmonics Impact on Digital Relays. Energies 2018, 11, 893. [CrossRef]

11. Sang-Ick, L.; Jae-Geun, Y.; Hyun-Jae, J. Design and Development of Distorted Source Device for Circuit Breakers Failure Analysis. In Proceedings of the International Conference on Power Electronics, Poznan, Poland, 1-3 September 2008; pp. 411-413.

12. Collombet, M.; Lacroix, B. LV circuit-breakers confronted with harmonic, transient and cyclic currents. Cahier Tech. Merlin Gerin 2011, 182, 2.

13. International Vocabulary of Metrology_Basic and General Concepts and Associated Terms (VIPM), 3rd ed.; JCGM 200:2012; Joint Committee for Guides in Metrology: Paris, Sèvres, France, 2012; p. 200.

14. Byoung, K.-C.; Sung-Tae, K.; Kil-Young, A.; Young-Geun, K. A Study on Electrical Lifespan of VI By means of Calculation of Arc Energy During Arcing Time in Synthetic Tests. In Proceedings of the International Conference on Electric Power Equipment, Busan, Korea, 25-28 October 2015; pp. 81-84.

15. Ke, Z.; Lidong, X.; Yaojia, Z.; Li, W. Characteristics Analysis of AC Arc Fault in Time and Frequency Domain. In Proceedings of the Prognostics and System Health Management Conference, Harbin, China, 9-12 July 2017; pp. 1-5.

16. Sekulic, W.R.; McNutt, P. Evaluating the Incident Energy of Arcs in Photovoltaic DC Systems: Comparison Between Calculated and Experimental Data. IEEE Trans. Ind. Appl. 2020, 56, 3224-3230. [CrossRef]

17. Fan, S.; Zhang, H.; Niu, C.; Chen, T.; Wu, Y.; Duan, Y.; Sun, H. Time-resolved Radiation Measurement and Energy Balance of Air Arcs. In Proceedings of the International Conference on Electric Power EquipmentSwitching Technology, Xi'an, China, 22-25 October 2017; pp. 200-203.

18. Sritrai, E.; Kittiratsatcha, S.; Polmai, S. Low Voltage Series Arc Fault Detection Using Rogowski Coil. In Proceedings of the International Conference on Engineering, Applied Sciences, and Technology, Phuket, Thailand, 4-7 July 2018; pp. 1-4.

19. Inada, Y.; Kikuchi, R.; Nagai, H.; Yamano, Y.; Maeyama, M.; Iwabuchi, H.; Kumada, A.; Hidaka, K.; Kaneko, E. A Systematic Comparison of Intense-Mode Vacuum Arc Between $\mathrm{CuCr}$ and AgWC Electrode by Using Various Optical Diagnostics. IEEE Trans. Plasma Sci. 2020, 48, 2224-2236. [CrossRef]

20. Donen, T.; Takai, Y.; Ochi, S. Effect of Arcing Time with Capacitive Making Current on Contact Welding in Vacuum. In Proceedings of the International Symposium on Discharges and Electrical Insulation in Vacuum, Greifswald, Germany, 23-28 September 2018; pp. 197-200.

21. Obarčanin., K.; Ostojić, R.; Džuzdanović, S. Parameters for Condition Assessment of the High Voltage Circuit Breakers Arcing Contacts using Dynamic Resistance Measurement. In Proceedings of the International Convention on Information and Communication Technology, Electronics and Microelectronics, Opatija, Croatia, 22-26 May 2017; pp. 1044-1048.

22. Borkowski, P.; Walczuk, E. The Aging of the Power Contacts Caused by Switching Current. In Proceedings of the International Conference on Electrical Contacts, Dresden, Germany, 22-26 June 2014; pp. 207-214.

23. Project 117-Elliott Sound Products. Available online: http://sound.whsites.net/project117.htm (accessed on 6 March 2020).

24. IEEE. 1459-2010 Standard Definitions for the Measurement of Electric Power Quantities Under Sinusoidal, Nonsinusoidal, Balanced, or Unbalanced Conditions; IEEE: New York, NY, USA, 2010.

(C) 2020 by the authors. Licensee MDPI, Basel, Switzerland. This article is an open access article distributed under the terms and conditions of the Creative Commons Attribution (CC BY) license (http://creativecommons.org/licenses/by/4.0/). 